Article

\title{
Functional Fitness and Quality of Life among Women over 60 Years of Age Depending on Their Level of Objectively Measured Physical Activity
}

\author{
Agnieszka Nawrocka ${ }^{1, *}$, Jacek Polechoński ${ }^{1}$, Wiesław Garbaciak ${ }^{2}$ and Władysław Mynarski ${ }^{1}$ \\ 1 Department of Physical Activity and Health Prevention, The Jerzy Kukuczka Academy of Physical \\ Education in Katowice, 43-512 Katowice, Poland; j.polechonski@awf.katowice.pl (J.P.); \\ w.mynarski@awf.katowice.pl (W.M.) \\ 2 Department of Theory and Methodology of Physical Education, The Jerzy Kukuczka Academy of Physical \\ Education in Katowice, 43-512 Katowice, Poland; w.garbaciak@awf.katowice.pl \\ * Correspondence: a.nawrocka@awf.katowice.pl; Tel.: +48-32-207-5169
}

Received: 22 February 2019; Accepted: 17 March 2019; Published: 18 March 2019

check for updates

\begin{abstract}
The aim of this study was to identify the differences in functional fitness and quality of life among women over 60 years of age depending on their level of objectively measured physical activity (PA) according to Global Recommendations on Physical Activity for health. The study used a cross-sectional design with 213 female volunteers over 60 years of age. Physical activity was monitored for 7 days of the week using an Actigraph Gt3X monitor. The Senior Fitness Test battery and hand-grip strength tests were performed to assess functional fitness. Quality of life was self-reported using a short version of the World Health Organization Quality of Life questionnaire WHOQOL-bref. Women who met the PA recommendations achieved slightly better results in most functional tests and in all domains of quality of life. Significant differences were found in the upper body strength, dynamic balance, and social relationships domains of quality of life. Physical activity programs developed on the basis of World Health Organization (WHO) recommendations have the potential to improve functional fitness and quality of life. However, further experimental studies in this area are required.
\end{abstract}

Keywords: WHOQOL; senior fitness test; exercises; Actigraph; accelerometry; elderly; older adults; physical fitness

\section{Introduction}

Physical activity is one of the most important health behaviors, preventing many age-related problems. It is associated with successful aging [1-3]. There is a lot of research evidence that physical activity reduces the risk of many noncommunicable diseases, including cancer, coronary diseases, diabetes, and pulmonary diseases [4-6]. Regular physical activity can also improve mental health, cognitive functions, and overall well-being [7-10]. Many studies have confirmed that people that are more physically active have a lower rate of overall mortality [11,12].

Therefore, a minimal level of physical activity is promoted by many international and national organizations for maintaining the health and functional capacity of societies. The best known and documented are the Global Recommendations on Physical Activity for Health developed by the World Health Organization (WHO) [13]. In these guidelines, an accumulation of at least 150 min of moderate physical activity (MPA) or at least 75 minutes of vigorous physical activity (VPA) during the week is considered as a bare minimum for adults and older adults. It is recommended to increase physical activity up to $300 \mathrm{~min}$ of MPA or $150 \mathrm{~min}$ of VPA per week to achieve more health benefits. 
Considering the fact that the world's population is aging, special attention should be paid to the health behaviors of older people. The participation of seniors in physical activity has a beneficial effect on functional ability and reduces the risk of functional limitations [14,15]. It allows them to maintain independence and keep self-reliance, which is very important for good quality of life. Therefore, the monitoring of percentages of adults and older adults who meet recommendations with respect to physical activity for health is an important and current research problem [16-18].

The relationship between various parameters of physical activity and functional fitness among older adults was confirmed in the previous studies $[19,20]$. Some researchers also emphasized the association between physical activity and quality of life among middle-aged and older adults [21-23]. However, the physical activity was measured using subjective self-reported assessment methods (questionnaires). It was confirmed that self-reported physical activity is often overestimated [24,25].

Therefore, the aim of this study was to identify the differences in functional fitness and quality of life among women over 60 years of age depending on their level of objectively measured physical activity according to the Global Recommendations on Physical Activity for health.

\section{Materials and Methods}

\subsection{Participants}

This study was approved by the ethical committee of the Jerzy Kukuczka Academy of Physical Education in Katowice. The study used a cross-sectional design with 213 women over 60 years of age.

All participants were volunteers from clubs and universities for seniors from urban regions near Katowice, Poland. The research project was promoted in all clubs and universities for seniors located in Katowice and adjacent cities through promotional posters and leaflets. People interested in participation in the research were invited to meetings, where the aim of the study, protocol, and research tools were presented. The inclusion criteria for participation in the study were as follows: age over 60 years, female gender, and agreement to participate in the full study protocol (functional fitness assessment, weekly monitoring of physical activity using the Actigraph monitor, and quality of life assessment using questionnaire). Participants with health conditions not allowing fitness test participation, and/or with any acute illnesses and musculoskeletal injuries were excluded. The total number of participants was 213, after including only women who met the inclusion criteria, had undergone the full research program, and had complete data from all measurements according to adopted criteria described in the methodology section. Women with missing data were excluded from analysis. More detailed participant characteristics are presented in Table 1. 
Table 1. Participant characteristics.

\begin{tabular}{|c|c|c|}
\hline Variables & $n$ & $\%$ \\
\hline \multicolumn{3}{|c|}{ Age (years) } \\
\hline $60-64$ & 70 & 32.9 \\
\hline $65-69$ & 74 & 34.7 \\
\hline $70-74$ & 43 & 20.2 \\
\hline $75-79$ & 17 & 8.0 \\
\hline $80-85$ & 9 & 4.2 \\
\hline Total & 213 & 100.0 \\
\hline \multicolumn{3}{|c|}{ BMI } \\
\hline $18-24.9$ & 53 & 24.9 \\
\hline $25-29.9$ & 73 & 34.3 \\
\hline $30-34.9$ & 56 & 26.3 \\
\hline $35-39.9$ & 23 & 10.8 \\
\hline $40-45$ & 8 & 3.8 \\
\hline Total & 213 & 100.0 \\
\hline \multicolumn{3}{|c|}{ Physical Activity (min/week) } \\
\hline $\mathrm{MPA}>150$ & 104 & 49.1 \\
\hline $\mathrm{MPA}>300$ & 72 & 33.8 \\
\hline $\mathrm{VPA}>75$ & 3 & 1.4 \\
\hline \multicolumn{3}{|c|}{ PA Recommendations } \\
\hline Met & 105 & 49.3 \\
\hline Not met & 108 & 50.7 \\
\hline
\end{tabular}

\subsection{Physical Activity Assessment}

Physical activity was recorded for seven consecutive days using a tri-axial accelerometer Actigraph Gt3X (ActiGraph, Pensacola, Florida) worn on the waistband. Data from Actigraph were processed using the following settings:

- Acceleration were accumulated from three axes (vertical, medio-lateral, anterio-posterior) and combined into a vector magnitude score (VM);

- A valid day was defined as a minimum of $10 \mathrm{~h}$ of wear time;

- Data were integrated into 60-second epochs and expressed as counts per minute (cpm);

- Non-wear time was defined as 60 consecutive minutes of $0 \mathrm{cpm}$, with allowance for 1-2 minutes of counts 0-200 cpm (Troiano algorithm modified for VM data) [26,27];

- The raw data from Actigraph were analyzed using Actilife v5 software (ActiGraph, Pensacola, FL, USA) and three levels of physical activity were identified according to following threshold counts values: 200-2689 cpm for light physical activity (LPA), 2690-6166 cpm for moderate intensity of physical activity (MPA), and more than $6167 \mathrm{cpm}$ for vigorous intensity of physical activity (VPA) [28]. Physical activity was assessed according to Global Recommendations on Physical Activity for Health developed by World Health Organization (WHO) [13]. Therefore, women who accumulated at least $150 \mathrm{~min}$ of moderate physical activity or at least $75 \mathrm{~min}$ of vigorous physical activity or combination of moderate and vigorous activity during the week were considered to be sufficiently physically active.

\subsection{Functional Fitness Assessment}

The Senior Fitness Test was used to measure physical parameters associated with functional ability [1]. This test is designed for people over 60 years of age, and consists of a six-item test:

- 8-Foot Up and Go-to assess agility/dynamic balance. Number of seconds required to get up from the chair, walk a distance of 8 feet $(2.44 \mathrm{~m})$, turn, and return to the seated position. 
- 30-Second Chair Stand-to assess lower body strength. Number of full stands in $30 \mathrm{~s}$ with arms folded across the chest.

- Arm Curl-to assess upper body strength. Number of full curls in $30 \mathrm{~s}$ holding a hand weight of $2 \mathrm{~kg}$.

- Back Scratch-to assess upper body flexibility. With one hand reaching over the shoulder and the other hand in the middle of the back. The result was the number of centimeters between extended middle fingers $(+$ or - ).

- Chair Sit and Reach-to assess lower body flexibility. Test was performed in a sitting position in front of a chair, with one leg extended and hands reaching as far as possible toward toes. The result of this trial was the distance calculated in centimeters (+ or -) between extended fingers and tip of the toes.

- 2-minute Step Test-This test was used as alternate aerobic endurance test because of space limitation

Additionally, the hand grip strength was measured using the hand-held hydraulic dynamometer JAMAR (Model J00105, Lafayette Instrument Company). The measurement was taken in the standing position with a fully extended elbow. For analysis the best result (in $\mathrm{kg}$ ) obtained from three reps was selected.

\subsection{Quality of Life Assessment}

Quality of life was assessed using a short form of the standardized the World Health Organization Quality of Life questionnaire WHOQOL-bref in a Polish version. This questionnaire contains 26 questions and allows for recognition of the individual's perception of quality of life in four domains [29]:

1. Physical health (activities of daily living, dependence on medicinal substances and medical aids, energy and fatigue, mobility pain and discomfort, sleep and rest, work capacity);

2. Psychological (bodily image and appearance, negative and feelings, self-esteem, thinking, learning, memory and concentration);

3. Social relationships (personal relationships, social support, sexual activity);

4. Environment (financial resources, freedom, physical safety and security, health and social care-accessibility and quality, home environment, opportunities for acquiring new information and skills, participation in and opportunities for leisure activities, physical environment, transport).

The questionnaire was self-administrated by participants. Domain scores were scaled in a positive direction (higher scores denote higher quality of life). The scores from questionnaire were calculated according to WHOQOL manual and the raw scores were converted to a scale of 1-100.

\subsection{Statistical Analysis}

Basic features of the data in this study were described using: statistical means (M) and standard deviations (SD) for quantitative data, and frequencies or percentages for qualitative data. The differences in the scores obtained in the Senior Fitness Test battery, hand-grip strength and quality of life between women who met and did not meet the physical activity recommendations were identified using non-parametric Mann-Whitney $U$ test. The association between meeting PA recommendations and the percentage of women with functional fitness assessed in the range of normal values for the age were assessed using Fisher's exact test.

All analyses were performed using IBM SPSS 20 software (IBM Corp. Released 2011. IBM SPSS Statistics for Windows, Version 20.0. Armonk, NY, USA). The level of significance of $p$-value was set at 0.05 . 


\section{Results}

The women who met physical activity (PA) recommendations achieved better results in all functional tests except a 2-min step trial (Table 2). The most significant differences were found in dynamic balance assessed by 8 -foot Up and Go test. The physically active women needed less time to perform this trial $(p<0.001)$. The upper body strength was significantly higher among women who met PA recommendations in comparison to women who were insufficiently active. The significant differences were found in both the arm curl $(p<0.004)$ and hand-grip $(p<0.010)$ strength test.

Table 2. Functional fitness of women who met and did not meet the physical activity (PA) recommendations.

\begin{tabular}{cccccc}
\hline \multirow{2}{*}{ Fitness tests } & \multicolumn{3}{c}{ Physical Activity Recommendations } & \multirow{2}{*}{$p$} \\
\cline { 2 - 5 } & \multicolumn{1}{c}{ Not Met $(\boldsymbol{n = \mathbf { 1 0 8 } )}$} & \multicolumn{2}{c}{ Met $(\boldsymbol{n = 1 0 5 )}$} & \\
\cline { 2 - 5 } & Mean & SD & Mean & SD & $\mathbf{0 . 0 0 1}$ \\
\hline 8-Foot Up and Go (seconds) & 7.01 & 2.19 & 6.20 & 1.25 & 0.162 \\
Chair stand (No. of stands) & 14.36 & 3.27 & 14.92 & 3.59 & $\mathbf{0 . 0 0 4}$ \\
Arm Curl (No. of reps) & 16.04 & 4.03 & 17.87 & 3.76 & 0.418 \\
Chair Sit-and-Reach (cm +/-) & 5.49 & 9.99 & 4.52 & 8.43 & 0.332 \\
Back Scratch (cm +/-) & -8.94 & 12.53 & -6.77 & 10.53 & 0.164 \\
2-Min Step (number of steps) & 87.31 & 25.06 & 82.61 & 25.89 & $\mathbf{0 . 0 1 0}$ \\
Hand-Grip Strength (kg) & 22.87 & 5.05 & 24.99 & 5.60 & \\
\hline
\end{tabular}

SD—standard deviation, Statistically significant differences at $p \leq 0.05$ are given in bold.

According to the Senior Fitness Test (SFT) manual, the results of senior fitness test were compared to the normal range of scores for women in various age groups. It should be noted that regardless of physical activity level, the functional fitness of examined women was good. In the majority of trials more than $50 \%$ of women achieved scores that can be considered as average or above average for their age (Table 3). The most limitations in functional fitness were found in the flexibility of the upper body (back scratch test). Less than $50 \%$ of women presented at least an average level of flexibility ( $42.6 \%$ of women who did not meet PA recommendations and $47.1 \%$ of women who met PA recommendations).

Table 3. Results of the Senior Fitness Test (SFT) according to norm for the age among women who met and did not meet the physical activity recommendations.

\begin{tabular}{|c|c|c|c|c|}
\hline \multirow{2}{*}{ Senior Fitness Test } & \multirow{2}{*}{ Normal Ranges } & \multicolumn{2}{|c|}{ Physical Activity Recommendations } & \multirow{2}{*}{$p$} \\
\hline & & Not Met $(n=108)$ & Met $(n=105)$ & \\
\hline \multirow{2}{*}{ 8-Foot Up and Go (seconds) } & Below & $40.7 \%$ & $38.5 \%$ & \multirow{2}{*}{0.780} \\
\hline & Average/Above & $59.3 \%$ & $61.5 \%$ & \\
\hline \multirow{2}{*}{ Chair stand (number of stands) } & Below & $10.2 \%$ & $13.5 \%$ & \multirow[b]{2}{*}{0.526} \\
\hline & Average/Above & $89.8 \%$ & $86.5 \%$ & \\
\hline \multirow{2}{*}{ Arm Curl (number of reps) } & Below & $13.9 \%$ & $3.8 \%$ & \multirow{2}{*}{0.015} \\
\hline & Average/Above & $86.1 \%$ & $96.2 \%$ & \\
\hline \multirow{2}{*}{ Chair Sit and Reach $(\mathrm{cm}+/-)$} & Below & $20.4 \%$ & $15.4 \%$ & \multirow{2}{*}{0.375} \\
\hline & Average/Above & $79.6 \%$ & $84.6 \%$ & \\
\hline \multirow{2}{*}{ Back Scratch $(\mathrm{cm}+/-)$} & Below & $57.4 \%$ & $52.9 \%$ & \multirow{2}{*}{0.581} \\
\hline & Average/Above & $42.6 \%$ & $47.1 \%$ & \\
\hline \multirow{2}{*}{ 2-Min Step (number of steps) } & Below & $25.9 \%$ & $33.7 \%$ & \multirow[b]{2}{*}{0.232} \\
\hline & Average/Above & $74.1 \%$ & $66.3 \%$ & \\
\hline
\end{tabular}

Statistically significant differences at $p \leq 0.05$ are given in bold.

The analysis of quality of life in various domain depending on level of physical activity showed that senior women who met the physical activity recommendations achieved better quality of life. The mean scores in all four domain were higher among women who were physically active in comparison to women who did not meet PA guidelines. However, significant differences were found only in the social relationships domain (Table 4). The mean score in this domain was $70.63 \pm 17.11$ among women with a sedentary lifestyle, and women with the recommended level of physical activity achieved a score of $74.88 \pm 14.04$. General quality of life was also higher among 
physically active women $(69.14 \pm 8.75)$ in comparison to less active senior women $(67.15 \pm 10.99)$. However, this difference was not statistically important.

Table 4. Quality of life (QoL) in various domains depending on meeting of physical activity recommendations.

\begin{tabular}{|c|c|c|c|c|c|}
\hline \multirow{3}{*}{$\begin{array}{c}\text { Domains of Quality of } \\
\text { Life (QoL) }\end{array}$} & \multicolumn{4}{|c|}{ Physical Activity Recommendations } & \multirow{3}{*}{$p$} \\
\hline & \multicolumn{2}{|c|}{ Not Met } & \multicolumn{2}{|c|}{ Met } & \\
\hline & Mean & SD & Mean & SD & \\
\hline Physical health & 59.94 & 12.43 & 61.12 & 8.63 & 0.567 \\
\hline Psychological & 64.23 & 12.58 & 65.81 & 11.41 & 0.476 \\
\hline Social relationships & 70.63 & 17.11 & 74.88 & 14.04 & 0.038 \\
\hline Environment & 73.81 & 12.62 & 74.76 & 11.77 & 0.714 \\
\hline QoL general & 67.15 & 10.99 & 69.14 & 8.75 & 0.273 \\
\hline
\end{tabular}

Statistically significant differences at $p \leq 0.05$ are given in bold.

\section{Discussion}

The main purpose of this study was to identify the differences in functional capacity and quality of life among women over 60 years of age depending on the Global Recommendations on Physical Activity for Health. In our study $49 \%$ of women accumulated during the week the recommended dose of moderate or vigorous physical activity. According to the previous study, this result should be considered very optimistic. In the study performed by Shiroma, et al. [30] the percentage of older women who accumulated at least $150 \mathrm{~min}$ /week of moderate or vigorous physical activity, on the basis of measurement with the same cut-points settings $(2690 \mathrm{cpm})$ was only $19.3 \%$. However, participants in this study were volunteers from centers and universities for seniors. These types of institutions implement educational and promotional programs of health activities, which might have resulted in better health behaviors of participants.

In our study women who met physical activity recommendations achieved better results in senior fitness tests, especially in dynamic balance and upper body strength. The relationship between physical activity and functional fitness among older adults was confirmed in other studies [20,31,32]. In our study also the hand-grip strength was higher $(2.12 \mathrm{~kg})$ among women who met the PA recommendations. The similar results were reported by Laddu et al. [33]. In their research, the high PA groups ( $\geq 1200$ metabolic equivalent (MET)-min/week) had stronger grip strength, more chair stands, and faster gait speeds than sedentary women.

Our study demonstrated that level of physical activity is significantly associated with social relationships domain of quality of life (QoL). However, regardless of domain, slightly better scores of QoL were identified among physically active women in comparison to insufficiently physically active participants. The positive influence of physical activity on quality of life was presented in many other studies [34-39]. Vagetti et al. [23] indicated that weekly volume of moderate and vigorous physical activity (MVPA) was associated with several domains of QoL, and higher frequency of MVPA was associated with better scores in 10 QoL domains.

In another study performed with the Polish population by Puciato et al. [40] using the WHOQOL-bref questionnaire, the odds of high assessment of overall quality of life increased with respondents' physical activity level. However, in contrast to our study, physical activity was estimated using the International Physical Activity Questionnaire (IPAQ), while we measured physical activity by tri-axial accelerometers.

Participants in our study were recruited from centers and universities for seniors. The relationship between levels of physical activity and quality of life among students of universities for seniors was recognized by Krzepota, et al. [41]. They showed that highly active seniors declared better QoL in the psychological and social domains more often than other respondents. However, also in this study the physical activity was estimated using IPAQ questionnaire. 
The most significant relationships between meeting of physical activity recommendations and quality of life were found in the social relationships domain. This domain was also significantly related to physical activity level in other studies [36,41].

\section{Strength and Limitation of the Study}

The main strength of this study is the use of accelerometers for identification of physical activity levels. This guarantees greater accuracy of the results in comparison to self-reported physical activity. The main limitation of this study is cross-sectional design with a convenience sample. Therefore, future studies should focus on the evaluation of the effects of implemented physical activity programs on functional fitness and quality of life among older adults.

\section{Conclusions}

There is an association between meeting physical activity recommendations and functional fitness and quality of life among women over 60 years of age. Physical activity programs developed on the basis of WHO recommendations have the potential to improve functional capacity and quality of life among aging women. However, further experimental studies in this area are needed.

Author Contributions: Conceptualization, A.N. and W.M.; Formal analysis, A.N. and J.P.; Investigation, A.N., J.P. and W.G.; Methodology, A.N., J.P., W.G., and W.M.; Supervision, A.N., W.G., and W.M.; Visualization, A.N. and W.M.; Writing—original draft, A.N.; Writing—review and editing, A.N., J.P., W.G., and W.M.

Funding: This research received no external funding.

Conflicts of Interest: The authors declare no conflict of interest.

\section{References}

1. Gopinath, B.; Kifley, A.; Flood, V.M.; Mitchell, P. Physical Activity as a Determinant of Successful Aging over Ten Years. Sci. Rep. 2018, 8, 10522. [CrossRef]

2. Arem, H.; Matthews, C.E.; Lee, I.M. Physical Activity Is Key for Successful Aging-Reply: Even a Little Is Good. JAMA Intern. Med. 2015, 175, 1863. [CrossRef] [PubMed]

3. Sasaki, J. Physical activity and successful aging. Nihon Ronen Igakkai Zasshi 2012, 49, 171-174. [CrossRef] [PubMed]

4. Warburton, D.E.R.; Bredin, S.S.D. Health benefits of physical activity: A systematic review of current systematic reviews. Curr. Opin. Cardiol. 2017, 32, 541-556. [CrossRef] [PubMed]

5. Reiner, M.; Niermann, C.; Jekauc, D.; Woll, A. Long-term health benefits of physical activity-A systematic review of longitudinal studies. BMC Public Health 2013, 13, 813. [CrossRef]

6. Kokkinos, P. Physical activity, health benefits, and mortality risk. ISRN Cardiol. 2012, 2012, 718789. [CrossRef]

7. Reas, E.T.; Laughlin, G.A.; Bergstrom, J.; Kritz-Silverstein, D.; Richard, E.L.; Barrett-Connor, E.; McEvoy, L.K. Lifetime physical activity and late-life cognitive function: The Rancho Bernardo study. Age Ageing 2019. [CrossRef]

8. Bademli, K.; Lok, N.; Canbaz, M.; Lok, S. Effects of Physical Activity Program on cognitive function and sleep quality in elderly with mild cognitive impairment: A randomized controlled trial. Perspect. Psychiatr. Care 2018. [CrossRef]

9. Delle Fave, A.; Bassi, M.; Boccaletti, E.S.; Roncaglione, C.; Bernardelli, G.; Mari, D. Promoting Well-Being in Old Age: The Psychological Benefits of Two Training Programs of Adapted Physical Activity. Front. Psychol. 2018, 9, 828. [CrossRef]

10. Panza, G.A.; Taylor, B.A.; Thompson, P.D.; White, C.M.; Pescatello, L.S. Physical activity intensity and subjective well-being in healthy adults. J. Health Psychol. 2017. [CrossRef]

11. Sakaue, A.; Adachi, H.; Enomoto, M.; Fukami, A.; Kumagai, E.; Nakamura, S.; Nohara, Y.; Kono, S.; Nakao, E.; Morikawa, N.; et al. Association between physical activity, occupational sitting time and mortality in a general population: An 18-year prospective survey in Tanushimaru, Japan. Eur. J. Prev. Cardiol. 2018. [CrossRef] 
12. Saint-Maurice, P.F.; Troiano, R.P.; Matthews, C.E.; Kraus, W.E. Moderate-to-Vigorous Physical Activity and All-Cause Mortality: Do Bouts Matter? J. Am. Heart Assoc. 2018, 7. [CrossRef]

13. WHO. Global Recommendations on Physical Activity for Health. Available online: https://europepmc.org/ books/NBK305057 (accessed on 15 January 2019).

14. Paterson, D.H.; Warburton, D.E. Physical activity and functional limitations in older adults: A systematic review related to Canada's Physical Activity Guidelines. Int. J. Behave. Nutr. Phys. Act. 2010, 7, 38. [CrossRef]

15. McAuley, E.; Konopack, J.F.; Morris, K.S.; Motl, R.W.; Hu, L.; Doerksen, S.E.; Rosengren, K. Physical activity and functional limitations in older women: Influence of self-efficacy. J. Gerontol. B Psychol. Sci. Soc. Sci. 2006, 61, P270-P277. [CrossRef]

16. Thralls, K.J.; Levy, S.S. The Association Between Self-Reported Adherence to Physical Activity Recommendations and Criteria for Maintaining Physical Independence of Older Adults. J. Aging Phys. Act. 2018, 26, 171-176. [CrossRef]

17. Luzak, A.; Heier, M.; Thorand, B.; Laxy, M.; Nowak, D.; Peters, A.; Schulz, H.; Group, K.O.-S. Physical activity levels, duration pattern and adherence to WHO recommendations in German adults. PLoS ONE 2017, 12, e0172503. [CrossRef]

18. Nawrocka, A.; Mynarski, W. Objective Assessment of Adherence to Global Recommendations on Physical Activity for Health in Relation to Spirometric Values in Nonsmoker Women Aged 60-75 Years. J. Aging Phys. Act. 2017, 25, 123-127. [CrossRef]

19. Tomas, M.T.; Galan-Mercant, A.; Carnero, E.A.; Fernandes, B. Functional Capacity and Levels of Physical Activity in Aging: A 3-Year Follow-up. Front. Med. 2017, 4, 244. [CrossRef]

20. Gouveia, E.R.; Maia, J.A.; Beunen, G.P.; Blimkie, C.J.; Fena, E.M.; Freitas, D.L. Functional fitness and physical activity of Portuguese community-residing older adults. J. Aging Phys. Act. 2013, 21, 1-19. [CrossRef]

21. Puciato, D.; Borysiuk, Z.; Rozpara, M. Quality of life and physical activity in an older working-age population. Clin. Interv. Aging 2017, 12, 1627-1634. [CrossRef]

22. Haider, S.; Luger, E.; Kapan, A.; Titze, S.; Lackinger, C.; Schindler, K.E.; Dorner, T.E. Associations between daily physical activity, handgrip strength, muscle mass, physical performance and quality of life in prefrail and frail community-dwelling older adults. Qual. Life Res. 2016, 25, 3129-3138. [CrossRef] [PubMed]

23. Vagetti, G.C.; Barbosa Filho, V.C.; Moreira, N.B.; de Oliveira, V.; Mazzardo, O.; de Campos, W. The Association Between Physical Activity and Quality of Life Domains among Older Women. J. Aging Phys. Act. 2015, 23, 524-533. [CrossRef] [PubMed]

24. Hagstromer, M.; Ainsworth, B.E.; Oja, P.; Sjostrom, M. Comparison of a subjective and an objective measure of physical activity in a population sample. J. Phys. Act. Health 2010, 7, 541-550. [CrossRef] [PubMed]

25. Wick, K.; Faude, O.; Schwager, S.; Zahner, L.; Donath, L. Deviation between self-reported and measured occupational physical activity levels in office employees: Effects of age and body composition. Int. Arch. Occup. Environ. Health 2016, 89, 575-582. [CrossRef] [PubMed]

26. Aguilar-Farias, N.; Brown, W.J.; Peeters, G.M. ActiGraph GT3X+ cut-points for identifying sedentary behaviour in older adults in free-living environments. J. Sci. Med. Sport 2014, 17, 293-299. [CrossRef]

27. Troiano, R.P.; Berrigan, D.; Dodd, K.W.; Masse, L.C.; Tilert, T.; McDowell, M. Physical activity in the United States measured by accelerometer. Med. Sci. Sports Exerc. 2008, 40, 181-188. [CrossRef] [PubMed]

28. Sasaki, J.E.; John, D.; Freedson, P.S. Validation and comparison of ActiGraph activity monitors. J. Sci. Med. Sport 2011, 14, 411-416. [CrossRef]

29. WHO. Development of the World Health Organization WHOQOL-BREF quality of life assessment. Psychol. Med. 1998, 28, 551-558. [CrossRef]

30. Shiroma, E.J.; Cook, N.R.; Manson, J.E.; Buring, J.E.; Rimm, E.B.; Lee, I.M. Comparison of Self-Reported and Accelerometer-Assessed Physical Activity in Older Women. PLoS ONE 2015, 10, e0145950. [CrossRef]

31. Nawrocka, A.; Mynarski, W.; Cholewa, J. Adherence to physical activity guidelines and functional fitness of elderly women, using objective measurement. Ann. Agric. Environ. Med. 2017, 24, 632-635. [CrossRef]

32. Santos, D.A.; Silva, A.M.; Baptista, F.; Santos, R.; Vale, S.; Mota, J.; Sardinha, L.B. Sedentary behavior and physical activity are independently related to functional fitness in older adults. Exp. Gerontol. 2012, 47, 908-912. [CrossRef] [PubMed] 
33. Laddu, D.R.; Wertheim, B.C.; Garcia, D.O.; Brunner, R.; Groessl, E.; Shadyab, A.H.; Going, S.B.; LaMonte, M.J.; Cannell, B.; LeBoff, M.S.; et al. Associations between Self-Reported Physical Activity and Physical Performance Measures over Time in Postmenopausal Women: The Women's Health Initiative. J. Am. Geriatr. Soc. 2017, 65, 2176-2181. [CrossRef] [PubMed]

34. de Carvalho, E.D.; Valadares, A.L.; da Costa-Paiva, L.H.; Pedro, A.O.; Morais, S.S.; Pinto-Neto, A.M. Physical activity and quality of life in women aged 60 or older: Associated factors. Rev. Bras. Ginecol. Obstet. 2010, 32, 433-440.

35. da Fonte, E.; Feitosa, P.H.; de Oliveira Neto, L.T.; de Araujo, C.L.; Figueiroa, J.N.; Alves, J.G. Effects of a physical activity program on the quality of life among elderly people in Brazil. J. Family Med. Prim. Care 2016, 5, 139-142. [CrossRef]

36. Omorou, Y.A.; Erpelding, M.L.; Escalon, H.; Vuillemin, A. Contribution of taking part in sport to the association between physical activity and quality of life. Qual. Life Res. 2013, 22, 2021-2029. [CrossRef]

37. da Silveira Goncalves, A.K.; Gomes Canario, A.C.; Leitao Cabral, P.U.; da Silva, R.A.; Spyrides, M.H.; Giraldo, P.C.; Eleuterio, J., Jr. Impact of physical activity on quality of life in middle-aged women: A population based study. Rev. Bras. Ginecol. Obstet. 2011, 33, 408-413. [PubMed]

38. De Azevedo Guimaraes, A.C.; Baptista, F. Influence of habitual physical activity on the symptoms of climacterium/menopause and the quality of life of middle-aged women. Int. J. Womens Health 2011, 3, 319-328. [CrossRef]

39. Kim, J.; Im, J.S.; Choi, Y.H. Objectively measured sedentary behavior and moderate-to-vigorous physical activity on the health-related quality of life in US adults: The National Health and Nutrition Examination Survey 2003-2006. Qual. Life Res. 2017, 26, 1315-1326. [CrossRef]

40. Puciato, D.; Rozpara, M.; Borysiuk, Z. Physical Activity as a Determinant of Quality of Life in Working-Age People in Wroclaw, Poland. Int. J. Environ. Res. Public Health 2018, 15. [CrossRef]

41. Krzepota, J.; Biernat, E.; Florkiewicz, B. The Relationship between Levels of Physical Activity and Quality of Life among Students of the University of the Third Age. Cent. Eur. J. Public Health 2015, 23, 335-339. [CrossRef]

(C) 2019 by the authors. Licensee MDPI, Basel, Switzerland. This article is an open access article distributed under the terms and conditions of the Creative Commons Attribution (CC BY) license (http:/ / creativecommons.org/licenses/by/4.0/). 